Militarização e democracia no Rio de Janeiro: efeitos e legados da "pacificação" das favelas cariocas.

Revista Ensaios, vol. 14, jan-jun de 2019.

\title{
Militarização e democracia no Rio de Janeiro: efeitos e legados da "pacificação" das favelas cariocas.
}

Lia de Mattos Rocha ${ }^{1}$

Resumo: A partir do caso do programa de "Pacificação" de favelas no Rio de Janeiro, iniciado em 2008 e cujo objetivo foi combater a criminalidade violenta através da "ocupação" dessas localidades pela Polícia Militar, analiso os "efeitos"' da "pacificação" para além das fronteiras das favelas. Dez anos depois, e após ser realizado em 38 favelas, o fim do projeto foi anunciado durante a "intervenção federal" na segurança fluminense. Contudo, baseando-me em pesquisa etnográfica e na literatura, argumento que um dos "legados" das Unidades de Polícia Pacificadora foi a disseminação de um ordenamento social calcado na "militarização" da vida, que não é exclusivo do Brasil, mas cujas repercussões ficaram evidentes em nossos eventos políticos mais recentes.

Palavras-chave: militarização, pacificação, milícias, favelas, Rio de Janeiro.

\section{Militarization and democracy in Rio de Janeiro: effects and legacies of the "pacification" of favelas.}

Abstract: The Favelas' "Pacification" Program in Rio de Janeiro was launched in 2008, having as a goal to combat violent crime through the "occupation" of these localities by the Military Police. In this article I analyze the program "effects" beyond the favelas' borders. Ten years later, and after it had been carried out in 38 favelas, the project was ended during the "federal intervention" in Rio de Janeiro. Thence, based on bibliographic and ethnographic research, I argue that one of the "legacies" of the Pacifying Police Unity was the dissemination of a social order based on the "militarization" of life, which is not exclusive to Brazil, but whose repercussions were evident in our most recent political events.

Keywords: militarization; pacification, militias, favelas, Rio de Janeiro.

\footnotetext{
${ }^{1}$ Universidade do Estado do Rio de Janeiro (UERJ), Programa de Pós-Graduação em Ciências Sociais (PPCIS), Rio de Janeiro, RJ, Brasil. liarocha08@gmail.com.
} 
Militarização e democracia no Rio de Janeiro: efeitos e legados da "pacificação" das favelas cariocas.

Revista Ensaios, vol. 14, jan-jun de 2019.

O objetivo deste artigo é analisar a trajetória do programa de "pacificação" de favelas, buscando compreender - para além da avaliação sobre as causas de seu "fracasso" - que efeitos ou "legados" (ressignificando o termo com que essa e outras iniciativas foram tratadas durante o "ciclo dos megaeventos") ele deixou.

Este programa, inaugurado em 2008, representou à época uma mudança na política então vigente, quando as operações policiais eram frequentes nas favelas cariocas. Em função disso, os indicadores de homicídios eram altos (em 2007 eram 41,7 homicídios por cem mil habitantes, enquanto que a taxa do Brasil era 26,2, segundo o IPEA, 2018²), assim como os de violência policial (8,6 homicídios registrados como causados por intervenção de agente do Estado por cem mil habitantes, segundo Miranda, 2014, pp. 15). Em uma dessas operações, realizada em 2007 em uma grande favela carioca, 19 pessoas foram mortas, com evidentes sinais de execução, às vésperas da realização do Panamericano - e por isso esse evento ficou conhecido internacionalmente como a Chacina do Pan.

O Brasil tinha sido escolhido, no ano anterior, como país sede da Copa do Mundo de Futebol da Federação Internacional de Futebol (Fifa), que seria realizada em 2014. O Rio de Janeiro era também candidato a sede dos Jogos Olímpicos de 2016 (cuja decisão se deu em outubro de 2009, ou seja, menos de um ano após os eventos mencionados acima). A questão da segurança pública preocupava seus cidadãos há muitos anos, e uma série de iniciativas para combater a criminalidade violenta - identificada pelo senso comum como localizada nas favelas e operada pelos traficantes de drogas (Machado da Silva, 2010) - tinham falhado anteriormente ${ }^{3}$. Nesse contexto, a operação na favela Santa Marta realizada em Novembro de 2008 parecia ser apenas mais uma, repetindo o roteiro já estabelecido: a polícia subiria o morro, haveria troca de tiros com traficantes varejistas de drogas, apreensão de algumas armas e drogas (sempre pouca, comparada com a força aplicada), eventualmente mortes de moradores de favelas, membros das quadrilhas e

\footnotetext{
2 Produzido pelo Instituto de Pesquisa Econômica e Aplicada em parceria com o Fórum Brasileiro de Segurança Pública. Cf. Atlas da Violência, 2018. Disponível em: 〈http://www.ipea.gov.br/atlasviolencia/〉.

${ }^{3}$ Cf. Albernaz et al., 2007; Moraes Silva e Cano, 2007; Ribeiro et al., 2016.
} 
Militarização e democracia no Rio de Janeiro: efeitos e legados da "pacificação" das favelas cariocas.

Revista Ensaios, vol. 14, jan-jun de 2019.

policiais, e em seguida a polícia se retiraria, deixando os moradores a calcularem suas perdas. Mas dessa vez foi diferente, porque a polícia que subiu a favela ali permaneceu, para surpresa dos habitantes do local e dos policiais envolvidos também (Menezes, 2018, pp. 194).

Ainda que não houvesse qualquer anúncio oficial, foi a partir dessa primeira ocupação que começou a desenhar-se o que o Governo do Estado do Rio de Janeiro chamou posteriormente de "um dos mais importantes programas de Segurança Pública realizado no Brasil nas últimas décadas"4, o Programa de Pacificação de Favelas. A primeira Unidade de Polícia Pacificadora (UPP) foi inaugurada nessa mesma favela, um mês depois da ocupação, com 125 recrutas recém titulados. Tratam-se de postos da Polícia Militar dentro das favelas, com um contingente de policiais treinados especialmente para o policiamento de proximidade.

Desde então, o programa alcançou 38 favelas (a última UPP a ser inaugurada foi a de Vila Kennedy, na Zona Oeste, em Maio de 2014). Foi carro chefe para a reeleição do Governador Sérgio Cabral (2007-2014) e garantiu a eleição de seu sucessor, Luiz Fernando Pezão (2014-2018). A chamada "Pacificação" foi peça fundamental na construção do Rio de Janeiro como uma cidade receptora de mega-eventos e também indício de sua recuperação econômica e política, tributada à parceria entre os três níveis de governo (Lula da Silva no governo federal, Sergio Cabral no estadual e Eduardo Paes - à época do mesmo partido que Cabral - no municipal). E hoje encontra-se em fase de desmonte, tornando-se evidência da crise pela qual passa o estado, que enfrenta perda de divisas, de empregos, entre outras, e tem atualmente dois ex-governadores presos por corrupção. O anúncio de extinção de parte das UPPs, realizado no contexto da intervenção federal na segurança pública do estado ${ }^{5}$, marca seu fim após uma prolongada decadência, já que desde 2014 o crescimento do número de mortes por intervenção policial indicava

\footnotetext{
${ }^{4}$ Governo do Rio de Janeiro. (s/d.). O que é a UPP? Rio de Janeiro, Brasil: Unidade de Polícia Pacificadora do Rio de Janeiro, texto completo: http://www.upprj.com/index.php/o_que_e_upp, fecha de consulta 06 de Fevereiro em 2019.

${ }^{5}$ A intervenção durou de 19 de fevereiro até 31 de dezembro de 2018. Para maiores informações ver Rocha (2018a).
} 
Militarização e democracia no Rio de Janeiro: efeitos e legados da "pacificação" das favelas cariocas.

Revista Ensaios, vol. 14, jan-jun de 2019.

que a "pacificação" não estava funcionando (dados apresentados pelo Instituto de Segurança Pública em 2019) ${ }^{6}$.

A partir de trabalho de campo realizado desde 2011 em diversas favelas "pacificadas"7 e do diálogo com os trabalhos produzidos pelos colegas, argumento que o "fracasso" do projeto não pode ser justificativa para abandoná-lo enquanto problema sociológico. Pelo contrário, a análise do seu "fracasso" possibilita compreender seus "efeitos": evitando o caminho de discutir como a "pacificação" deveria ter sido, busco compreender como ela foi, que efeitos produziu e o que permanece dessa experiência. A partir desses dados, demonstro de que forma a "pacificação" deixa como "legado" a disseminação da militarização ${ }^{8}$ como dispositivo ${ }^{9}$ de disciplinamento, controle e tutela dos trabalhadores e pobres urbanos, dos moradores de favela e periferias e de todos aqueles classificados, dentro dessa lógica, como "insurgentes urbanos". A plataforma com a qual o atual presidente do Brasil, Jair Bolsonaro, foi eleito - marcada por discursos contrários à defesa dos Direitos Humanos e defendendo maior repressão e punições mais severas - é uma evidência dessa propagação. A propagação das milícias ${ }^{10}$ é outra.

\footnotetext{
${ }^{6}$ Cabe ressaltar que Christina Vital da Cunha identificou que o apoio midiático ao projeto das UPPs, frequente no seu começo, começa a esmorecer já a partir de meados de 2011, em função do reaparecimento nos jornais de notícias sobre episódios de violência. Cf. da Cunha, 2015.

${ }^{7}$ O trabalho de campo foi realizado entre 2011 e 2016 nas seguintes localidades: Morro dos Macacos, Cidades de Deus, São Carlos, Manguinhos e Caju. Para tal contei com financiamento do CNPq e da Fundação Carlos Chagas de Amparo à Ciência - Faperj. Sem esses financiamentos não teria produzido minhas pesquisas e artigos, que subsidiaram também o processo de formação de diversos pesquisadores brasileiros que comigo estudaram e trabalharam.

${ }^{8}$ Compreendo como militarização a aplicação de medidas consideradas tipicamente "de guerra" para a repressão do chamado crime comum (o que inclui também a repressão política). Assim, trata-se de um dispositivo que combina atuações do tipo militar (podendo ser realizadas por agentes militares ou não) com a disseminação de uma doutrina securitária que reordena a vida social, transformando todos os espaços em potenciais "campos de batalha" e todo tipo de insurgência em ameaça à segurança. Dessa forma, essa abordagem tenta ampliar o conceito de militarização para além da atuação estrita das Forças Armadas na conformação da vida social (do mundo "não militar"), ainda que reconhecendo a importância desses atores no processo. Mas nos tempos atuais a militarização está sendo operada por diversos atores e está presente em diversas dimensões da vida social. Sobre o tema ver Leite et. al.; 2018; Barros, 2018; entre outros.

${ }^{9}$ Inspiro-me obviamente no conceito foucaultiano de dispositivo (conforme apresentado em sua obra História da Sexualidade, volume 1, 2017), com todas as suas indefinições. Baseio-me, sobretudo, na definição apresentada pelo autor em uma entrevista, onde ele afirma que o dispositivo é "um conjunto decididamente heterogêneo que engloba discursos, instituições, organizações arquitetônicas, decisões regulamentares, leis, medidas administrativas, enunciados científicos, proposições filosóficas, morais, filantrópicas. Em suma, o dito e o não dito são os elementos do dispositivo. O dispositivo é a rede que se pode tecer entre estes elementos" (Foucault, 2000, p. 244).

${ }^{10}$ Milícias são grupos armados poderosos, que atuam em diversas favelas do Rio de Janeiro, tendo mais que dobrado sua área de atuação entre 2010 e 2017, segundo dados do Ministério Público do Rio de Janeiro:
} 
Militarização e democracia no Rio de Janeiro: efeitos e legados da "pacificação" das favelas cariocas.

Revista Ensaios, vol. 14, jan-jun de 2019.

Assim, é sobre o programa das UPPs, seus impactos e seus efeitos, para além de sua morte anunciada, que me detenho neste artigo.

\section{O Programa de Pacificação de favelas no Rio de Janeiro.}

As favelas no Rio de Janeiro são identificadas como o local da segregação social onde moram os pobres, os marginais, os não-civilizados. Desta representação estigmatizada decorrem diversas políticas públicas que reforçam a segregação, e dentre elas a política de segurança talvez seja a mais evidente. Dessa forma, se até os anos 1970 as políticas ali executadas caracterizavam-se ou pela remoção forçada de seus moradores para conjuntos habitacionais distantes do local original (Valadares, 1978; Pestana, 2018) ou por um forte viés assistencialista (Burgos, 1998; Carvalho, 2003; Valladares 2005), os últimos anos da ditadura militar (1964-1985) foram marcados pelo início dos confrontos entre as quadrilhas de traficantes varejistas de drogas e as forças policiais ${ }^{11}$.

A política de segurança executada pelo Estado do Rio de Janeiro oscilou entre momentos de extremo confronto - como quando se estabeleceu uma premiação por bravura que era quantificada pelo número de mortes causadas (a "gratificação faroeste" ${ }^{12}$ ) ou quando tanques de guerra foram colocados nas entradas das favelas durante a Conferência Rio +20 , conhecida como Operação Rio, e momentos em que projetos de uma polícia respeitadora dos direitos humanos foram referência - como o Grupamento de Polícia para Áreas Especiais, o Mutirão pela Paz e a Delegacia Legal ${ }^{13}$. Desde o final dos anos 1990 são essas duas perspectivas que disputam a orientação da politica de segurança

entre 2010 e 2017 o numero de localidades com atuação de milícia na cidade passou de 41 para 88. Disponível em: <https://oglobo.globo.com/rio/em-oito-anos-numero-de-areas-controladas-por-gruposparamilitares-dobrou-22574503 $\rangle$. Acessado em 01 de fevereiro de 2019

${ }^{11}$ Importante destacar que durante o primeiro governo Brizola (1983-1987), no período pós-ditadura, tentou-se implementar uma política fundiária, através do programa "Cada família um lote" (Cf. Gonçalves, 2006).

${ }^{12}$ Instituída pelo Governador Marcelo Alencar em 1995 por decreto, a "gratificação faroeste" previa um prêmio no valor de $50 \%$ a $150 \%$ do salário do Policial Militar caso seu desempenho fosse bem avaliado pelos superiores, valor que era incorporado ao salário. Como resultado, dois anos depois a média de mortos em relação aos feridos nas operações policiais passou de dois para quatro mortos, justificando o apelido que o prêmio ganhou. Somente em 2000 a gratificação foi extinta, pelo então Governador Anthony Garotinho. Sobre o assunto ver Leite, 2000.

${ }^{13}$ A bibliografia que analisa tais movimentos é extensa. Indico Leite, 2000; Machado da Silva (org.) 2008 e Farias, 2014 - sabendo que esse é apenas um fragmento do debate. 
Militarização e democracia no Rio de Janeiro: efeitos e legados da "pacificação" das favelas cariocas.

Revista Ensaios, vol. 14, jan-jun de 2019.

no estado (Leite, 2000). A UPP é, em muitos aspectos, devedora desta última perspectiva, que preconizava que as favelas não deveriam (ou não deveriam apenas) ser alvo de ações policiais e militares, mas também de políticas sociais.

É portanto neste contexto que o projeto da "pacificação" é apresentado: de inserção da cidade do Rio de Janeiro no circuito das cidades recebedoras de megaeventos (ciclo que começa exatamente em 2007, com os Jogos Panamericanos ${ }^{14}$ ), com altos índices de criminalidade e uma imagem internacional de cidade violenta (Miranda, 2014; Palermo, 2013). Assim, como tentativa de reverter esse cenário, e tendo em vista que o Rio de Janeiro já tinha sido selecionado como uma das cidade-sede da Copa do Mundo de 2014 e era candidata a cidade-sede dos Jogos Olímpicos de 2016, o programa é colocado em prática sem muita regulamentação ou planejamento (Menezes, 2018; Ribeiro e Villarouca, 2018).

Desde seu início, no final do ano de 2008, as UPPs contaram com enorme apoio por parte da grande mídia e de setores empresarias, sobretudo aqueles mais diretamente engajados no projeto de transformar o Rio de Janeiro em uma cidade de negócios, uma cidade empreendedora (Vainer, 2011; Ribeiro \& Santos Junior, 2013). Dentre os setores que ativamente participaram da execução do projeto, inclusive contribuindo financeiramente para sua realização, podemos destacar empresas dos setores petrolíferos, imobiliário e turístico (Burgos et al., 2011, pp. 55) ${ }^{15}$.

Da mesma forma, a grande mídia foi fundamental para a propaganda do programa, divulgando as iniciativas e garantindo que as críticas e questionamentos tivessem pouco espaço no debate público (Rocha e Palermo, 2015; Almendra, 2014).

\footnotetext{
${ }^{14} \mathrm{O}$ ciclo dos megaeventos no Rio de Janeiro correspondem aos seguintes eventos: Jogos Pan-Americanos (2007), Jogos Mundiais Militares (2011), Jornada Mundial da Juventude (2013, que reuniu cerca de 3,7 milhões de jovens católicos e foi o maior evento em termos de público participante), Copa do Mundo (2014) e finalmente os Jogos Olímpicos e Paraolímpicos (2016).

${ }^{15}$ Segundo Barros Vieira (2016) o grande empresário Eike Batista, do grupo de mineração EBX, se comprometeu em doar $\mathrm{R} \$ 20$ milhões anuais durante dois anos, a Bradesco Seguros doou $\mathrm{R} \$ 2$ milhões e empresas como a Coca-Cola, a Souza Cruz e Odebrecht bancaram ou realizaram a construção de diversas sedes para as UPPs (pp. 293). Da mesma forma, grandes "parceiros" do programa foram a Federação das Indústrias do Estado do Rio de Janeiro, a Firjan, o Banco Mundial e a Organização das Nações Unidas essa responsável por co-executar o programa UPP Social, a complementação social do programa (sobre a UPP Social ver Rocha e Carvalho, 2018).
} 
Militarização e democracia no Rio de Janeiro: efeitos e legados da "pacificação" das favelas cariocas.

Revista Ensaios, vol. 14, jan-jun de 2019.

O projeto das UPPs foi essencial para a inserção do Rio de Janeiro no mercado das cidades sede dos megaeventos, e por isso o planejamento de ocupação das favelas seguiu o desenho do circuito turístico, primeiro atingindo as favelas do que se convencionou chamar "cinturão olímpico" (Davies, 2017) - fundamentalmente o entorno do estádio do Maracanã. A preocupação em garantir segurança para os espectadores ${ }^{16}$ da Copa do Mundo e dos Jogos Olímpicos nunca foi um objetivo disfarçado, e provavelmente essa explícita correlação entre "pacificação" e megaeventos contribua para explicar porque o projeto foi recebido com desconfiança pelos parte dos moradores de favelas ("pacificadas" ou não). Em survey realizado entre 2014 e 2016 em diversas favelas "pacificadas", 43,4\% dos entrevistados afirmaram que a UPP iria acabar após as Olimpíadas (Ribeiro e Villarouca, 2018, pp. 1163). Contudo, a desconfiança em relação ao programa não se deve apenas à relação instrumental com os megaeventos - existe um evidente e reconhecido histórico de desconfiança dos moradores de favelas em relação a polícia (Burgos et al., 2011, pp. 92), resultado de um século de criminalização e violência estatal. Ainda assim, segundo Ribeiro e Villarouca (2018, pp. 1163) 75,8\% dos entrevistados afirmaram que a UPP deveria continuar. É válido destacar, contudo, que o desejo de continuidade das UPPs foi maior entre os entrevistados em 2014 do que entre os entrevistados em 2016 - 87\% vs. 64\%, respectivamente (2018, pp. 1169).

Em pesquisa realizada em 2011, Cano, Borges e Ribeiro (2012) analisam os indicadores de criminalidade e letalidade antes e após a instalação das UPPs (considerando o universo de unidades existentes à época), e demonstram como a taxa de mortes violentas cai a aproximadamente um quinto da anterior (de 10,03 mortes por cem mil habitantes para 2,21). Outro dado significativo que os autores apontam é a drástica redução do número de mortes em intervenção policial (registradas à época como auto de resistência, ou seja, morte causada por agente policial em situação de confronto), de 5,7 por cem mil habitantes para $0,12^{17}$. No mesmo sentido, demonstram como o efeito da redução das mortes não se deu apenas dentro das favelas "pacificadas", ampliando o escopo da análise para o entorno das localidades (Cano, Borges \& Ribeiro, 2012, pp. 106).

\footnotetext{
${ }^{16} \mathrm{O}$ objeto da atenção aqui era, fundamentalmente, o público estrangeiro, que iria consumir a cidade do Rio de Janeiro a partir da "embalagem" da "pacificação" (Miranda, 2014, pp. 8)

${ }^{17}$ Para produzir esses indicadores os pesquisadores utilizaram dados do Instituto de Segurança Pública do Estado do Rio de Janeiro. Para acessar as informações ver: 〈http://www.isp.rj.gov.br〉.
} 
Militarização e democracia no Rio de Janeiro: efeitos e legados da "pacificação" das favelas cariocas.

Revista Ensaios, vol. 14, jan-jun de 2019.

Os dados apresentados acima indicam um impacto significativo nos índices de letalidade no período inicial de implantação do programa, mas nos anos seguintes tal resultado não foi similar, o que fez o programa perder parte de sua legitimidade ao longo dos dez anos de sua duração. Em outro sentido, pesquisadores argumentaram que a política da "pacificação" não representava uma mudança real da orientação da política de segurança, mas sim um conjunto de práticas de policiamento rearranjadas de forma a produzir um discurso inovador centrado na permanência da polícia nas favelas em oposição às operações policiais ${ }^{18}$.

Para os moradores de favelas "pacificadas", e também aqueles que vivem em seu entorno, o "fim dos tiroteios" - resultado direto da interrupção das operações policiais e de uma atuação menos ostensiva por parte das quadrilhas de traficantes varejistas de drogas (Menezes, 2018) - foi sem sombra de dúvida o mais importante resultado das UPPs. Ainda segundo Ribeiro e Villarouca (2018), os respondentes que afirmaram ter percebido uma redução dos tiroteios em suas localidades de moradia eram 3,3 vezes mais inclinados a desejar a continuidade do programa $(2018,1171)$. No mesmo sentido, Menezes (2018, pp. 206) indica que é exatamente quando os tiroteios começam a se tornar frequentes, e os traficantes começam a atuar de forma mais ostensiva novamente, que o programa se torna cada vez mais desacreditado. A autora afirma ainda que, nas duas favelas em que realizou sua pesquisa qualitativa, a principal desconfiança por parte dos moradores era que os traficantes haviam retornado porque teriam negociado com os policiais militares, através do pagamento de propinas - tradicional expediente de troca entre tais atores (Menezes, 2018, pp. 204; Misse, 2007).

Destarte, a mudança mais perceptível causada pela instalação das UPPs foi a redução dos confrontos armados e do número de mortes e, portanto, quando esses voltaram a acontecer nas favelas "pacificadas" a sensação geral foi que o projeto estava em "crise"19. Em termos da letalidade, observa-se no estado do Rio de Janeiro um

\footnotetext{
${ }^{18}$ Para críticas ao programa a partir da sua pouca "efetividade" ver Burgos, et. al, 2011; Machado da Silva, 2010; Miranda, 2014.

19 Sobre o tema ver matérias no El País e BBC disponíveis em: <https://brasil.elpais.com/brasil/2018/03/11/politica/1520769227_645322.html> < https://www.bbc.com/portuguese/brasil-37722864>. Consultado em: 〈05 de Fevereiro de 2019>.
} 
Militarização e democracia no Rio de Janeiro: efeitos e legados da "pacificação" das favelas cariocas.

Revista Ensaios, vol. 14, jan-jun de 2019.

crescimento no número de mortes violentas ${ }^{20}$ a partir de 2013 - alterando uma tendência de queda observada desde 2002 (antes do programa das UPPs). Mas o dado mais preocupante é o rápido crescimento dos indicadores de letalidade policial, ou morte por intervenção de agente do Estado, sendo o índice atual o maior desde 1998 (primeiro ano da série histórica apresentada): 9,0 mortes decorrentes de intervenção por agente de Estado por cem mil habitantes. Desde 2014 percebe-se uma tendência de crescimento no indicador, revertendo uma tendência de queda iniciada em $2008^{21}$. Vale destacar, ainda, o aumento no número de policiais mortos, tanto em serviço quanto de folga, especialmente entre 2016 e 2017 - o número tem aumentado desde 2012, revertendo uma tendência de queda observada a partir de 2004 (ISP, 2018).

Tais números demonstram que, pelo menos em termos de indicadores de criminalidade, o "efeito" da "pacificação" sobre a violência urbana no estado do Rio de Janeiro começou a esgotar-se entre os anos de 2013 e 2014. As causas para tanto ainda são objeto de discussão, e vão desde dificuldades institucionais - como as diferenças hierárquicas internas à polícia militar que estariam sendo desrespeitadas pelo modelo das UPPs - até a falta de financiamento necessário por conta da crise crise econômica do estado ocorrida após os megaeventos, passando por análises que caracterizam a instituição miliar como refratária à conceitos como policiamento de proximidade (Puff, 2016; Ribeiro et al. 2018). Outrossim, muitos pesquisadores reforçam que o modelo de "guerra às drogas" implementado nunca terá os efeitos pretendidos pela "pacificação", por estar baseado na criminalização da pobreza (na "guerra aos pobres") e não no combate às causas da violência (entre outros, cabe destacar Leite, 2017; Pacheco de Oliveira, 2014; Barros e Farias, 2017; Leite et. al, 2018)

Possivelmente, a confluência desses diversos fatores levaram ao ocaso do programa e, em abril de 2018, o ministro Extraordinário da Segurança Pública, Raul Jungmann, anunciou a extinção de 18 das 38 Unidades de Polícia Pacificadora (UPP) do estado, e a

\footnotetext{
${ }^{20}$ Segundo o Instituto de Segurança Pública do Estado do Rio de Janeiro, são contabilizados nessa categoria os seguintes tipos penais: homicídio doloso, roubo seguido de morte (latrocínio), lesão corporal seguida de morte e morte decorrente de intervenção de agente do Estado. Para maiores informações ver ISP (2018).

${ }^{21}$ Segundo o Instituto de Segurança Pública do Estado do Rio de Janeiro, em 2008 foram contabilizados 7,3 mortes decorrentes de ação de agente de Estado por cem mil habitantes, com uma tendência de queda até 2013 - que registrou 2,5 mortes por cem mil habitantes - e um crescimento a partir de 2014 chegando às 9,0 mortes por cem mil habitantes registradas em 2018. Para maiores detalhes ver ISP (2018).
} 
Militarização e democracia no Rio de Janeiro: efeitos e legados da "pacificação" das favelas cariocas.

Revista Ensaios, vol. 14, jan-jun de 2019.

incorporação de outras aos batalhões regulares de Polícia Militar. Mesmo antes do anúncio já se cogitava o fim do programa, especialmente desde a decretação da intervenção federal na área da Segurança, em fevereiro de 2018.

Desta forma, no momento em que o programa encontra-se desacreditado e em progressiva extinção, argumento que é fundamental compreendê-lo para além das causas de seu fracasso, mas conforme dito anteriormente, em uma perspectiva que considera os efeitos que a "pacificação" produziu e que permanecem para além de seu término. Somando-me à outras análises que apresento à seguir, compreendo que o "efeito" alcançado pelas UPPs (desconsiderando aqui suposições sobre intencionalidade ou objetivos instrumentais) foi o de disseminar dispositivos de disciplinarização sobre a população moradora de favelas.

Entre esses dispositivos destacam-se o aumento da vigilância estatal sobre os favelados (Burgos et al., 2011: 73), recuperando o significado do termo "pacificação" aplicado ao contexto da relação entre estado e população indígena no Brasil, conforme indicou Pacheco de Oliveira (2014): disciplina e tutela para aqueles considerados insuficientemente civilizados. Essa vigilância, por sua vez, pode ser também realizada por agentes não estatais, como alerta Menezes (2018), ao descrever o monitoramento múltiplo a que estão submetidos os moradores de favela, seja por parte da polícia - usando câmeras de vigilâncias celulares e até drones -, seja por parte dos traficantes - com a expansão do número de soldados na função de "olheiros"22 (Menezes, 2018: 210). A disseminação da vigilância e do monitoramento é possível pela proximidade que policiais passam a ter com os moradores das favelas que passam a ocupar, mas Barros e Farias (2018) argumentam que é essa mesma proximidade territorial que possibilita a atualização de antigos mecanismos de criminalização e execução de jovens favelados. É também a proximidade que alça os policiais militares à condição de atores políticos centrais na mediação entre organizações locais e o poder público, o que reforça a subordinação das políticas sociais e dos espaços de diálogo institucional à lógica do controle militarizado da criminalidade, como demonstram Araújo Silva e Carvalho (2015,

\footnotetext{
${ }^{22}$ Soldados são os membros das quadrilhas de tráfico varejista de drogas no Rio de Janeiro em posições hierárquicas inferiores. Olheiros são responsáveis por vigiar o território e alertar caso inimigos tentem se aproximar.
} 
Militarização e democracia no Rio de Janeiro: efeitos e legados da "pacificação" das favelas cariocas.

Revista Ensaios, vol. 14, jan-jun de 2019.

72). Por fim, o importante trabalho de Marcia Leite (2017) argumenta que a "pacificação" tem como efeito (e daí vem seu sucesso, ao contrário do que a ideia de "crise" dá a entender) a produção de uma tecnologia de poder replicável em outros contextos, e que tem circulado dentro e fora do país. Esta tecnologia possibilita disciplinar uma população de forma a enquadrar suas reivindicações por inclusão social na gramática do capitalismo ultraneoliberal (através das categorias empreendedorismo e inclusão produtiva), mas garantindo àqueles que não se adequam o silenciamento, a expulsão ("branca”, ou pelo mercado) e no limite o extermínio.

Dessa forma, proponho refletir sobre como a militarização, enquadrada aqui a partir da experiência da "pacificação" da cidade (para além das favelas ocupadas pelas forças militares), constitui um dispositivo que estende sua teia para além dessas localidades. Constitui um dos elementos desse dispositivo a subordinação das pastas e ações "sociais" da administração estadual e municipal às demandas por segurança e o disciplinamento da cidade e da sociedade. Os investimentos sociais, especialmente em favelas, só têm legitimidade pública quando pretendem resolver o "problema-favela", colocado em termos do risco que esses territórios e seus moradores representam para a paz da cidade e dos "cidadãos de bem". Outro elemento é a compreensão disseminada de que não há alternativa melhor que a atuação nesses locais dos aparelhos estatais de repressão, o que rebaixou a possibilidade de crítica ao programa da "pacificação" e à intervenção federal. Tal rebaixamento articula dois argumentos diferentes: i) o discurso criminalizante/moral, que rotula quem era contra a "pacificação" como a favor do retorno do controle territorial pelo tráfico de drogas (acionado especialmente contra fala de moradores de favelas e suas lideranças, a partir da criminalização desses atores, conforme discuti em Rocha, 2018b); e ii) o discurso "tecnocrático", que justifica a opção por esse modelo de política de segurança pública como o único possível (e se beneficia da contribuição ativa de pesquisadores da área). Na era da tecnocracia, a política é descrita como politicagem, e a pressão popular é desqualificada como incompetente para compreender a proposta e vista como influenciada por atores políticos que não representam os interesses da maioria. Assim, o discurso técnico - além do moral - também é acionado diversas vezes contra as demandas dos moradores das áreas de favelas (Rocha, Carvalho e Davies, 2018). 
Militarização e democracia no Rio de Janeiro: efeitos e legados da "pacificação" das favelas cariocas.

Revista Ensaios, vol. 14, jan-jun de 2019.

Na próxima e última seção, proponho discutir as consequências da militarização para o Rio de Janeiro e o Brasil, considerando a forma como tem se disseminado um ordenamento social calcado na "militarização" da vida, que não é exclusivo do Brasil mas cujas repercussões ficaram evidentes em nossos eventos políticos mais recentes.

\section{Da pacificação à eleição de Jair Bolsonaro: a ascensão da militarização no Rio} de Janeiro e no Brasil.

Em 29 de Outubro de 2018 Jair Bolsonaro, ex-capitão do Exército Brasileiro, foi eleito presidente do país em segundo turno, como $55 \%$ dos votos válidos. Na mesma data foram eleitos para as casas legislativas federais e estaduais 73 parlamentares que se identificaram oficialmente como militares ou policiais ${ }^{23}$. Bolsonaro e seus companheiros foram eleitos com um forte discurso contrário aos Direitos Humanos, reivindicando o período da ditadura militar (1964-1985), a tortura e a perseguição política e ameaçando varrer os "bandidos vermelhos". Após sua posse, em 01 de Janeiro de 2019, montou um governo onde militares ocupam sete ministérios (de um total de 22) e outros tantos postos importantes nos ministérios da Economia, Educação e Justiça, entre outros.

Sua eleição e seu governo são, até o momento, o ápice desse processo de penetração das Forças Armadas na vida política brasileira ${ }^{24}$, mas o processo é anterior. Zaverucha (2005) afirma que desde o governo Fernando Henrique Cardoso (1995-2002) os militares ocupam postos importantes nos governos civis e que nunca se subordinaram à autoridade civil do Ministério da Defesa, como previsto na Constituição, por conta do "legado autoritário herdado dos governos militares" (2005, pp. 107).

\footnotetext{
${ }^{23}$ Dados do Tribunal Superior Eleitoral do Brasil segundo o site G1, das Organizações Globo. Entre os 73 candidatos, 43 são filiados ao partido de Jair Bolsonaro, o Partido Social Liberal. O número de parlamentares eleitos que afirmaram ser bombeiro militar, policial civil ou militar, militar reformado ou membro das forças armadas é quatro vezes maior que o observado na eleição anterior, em 2014. Fonte: $<$ https://g1.globo.com/politica/eleicoes/2018/eleicao-em-numeros/noticia/2018/10/08/numero-depoliciais-e-militares-no-legislativo-e-quatro-vezes-maior-do-que-o-de-2014.ghtml >. Consultado em: <06 de fevereiro de 2019>.

${ }^{24}$ Segundo levantamento do jornal O Estado de São Paulo, o governo de Bolsonaro terá mais militares do que em 1964 (ano do Golpe Militar no Brasil). Disponível em: <https://politica.estadao.com.br/noticias/geral,numero-de-militares-no-1-escalao-e-o-maior-desde1964,70002647839>. Consultado em: <06 de fevereiro de 2018>.
} 
Militarização e democracia no Rio de Janeiro: efeitos e legados da "pacificação" das favelas cariocas.

Revista Ensaios, vol. 14, jan-jun de 2019.

Para além da presença nas estruturas governamentais, a presença dos militares se faz evidente nas ruas das grandes cidades brasileiras, especialmente através do dispositivo "Garantia da Lei e da Ordem", que concede provisoriamente aos militares a faculdade de atuar com poder de polícia até que sejam superadas as condições que levaram ao seu acionamento. Esses seriam os "casos em que há o esgotamento das forças tradicionais de segurança pública, em graves situações de perturbação da ordem”, segundo o site do Ministério da Defesa. Ainda segundo o Ministério, nessas ações as Forças Armadas agem de forma "episódica, em área restrita e por tempo limitado, com o objetivo de preservar a ordem pública, a integridade da população e garantir o funcionamento regular das instituições" (Ministério da Defesa, 2019) ${ }^{25}$. Os militares já atuaram a partir da "Garantia da Lei e da Ordem" em quatro estados brasileiros, na repressão à manifestações em Brasilia e em ações em 34 presídios. Para proporcionar condições legais para a atuação das Forças Armadas nessas operações, o ex-presidente Michel Temer decretou em agosto de 2017 que militares acusados de crimes dolosos praticados contra a vida de civis quando em atividade operacional só poderão ser julgados por tribunais militares, modificando lei de 1996 que garantia que tais acusações seriam julgadas por tribunais de júri da justiça comum.

No caso do Rio de Janeiro, especificamente, as Forças Armadas - em operações de GLO - ocuparam dois grandes conjuntos de favelas cariocas: o Alemão (quase 70 mil habitantes segundo o Censo de 2010, ocupado entre 2010 e 2012) e a Maré (quase 130 mil habitantes, também segundo o Censo de 2010, e ocupada entre 2014 e 2015). Também participaram da segurança em diversas eleições (desde a eleição municipal de 2008), nos momentos dos grandes eventos (Jogos Mundiais Militares em 2011, Jornada Mundial da Juventude em 2013, Copa do Mundo em 2014 e Jogos Olímpicos em 2016) e na repressão a manifestações contrárias à votação do pacote de austeridade do governo Pezão (PMDB) em 2017.

O uso dispositivo da GLO em situações tão variadas, desde as ocupações do Exército na Maré e no Alemão até a repressão a manifestações contra o governo indica

\footnotetext{
${ }^{25}$ Ministério da Defesa (2019). Garantia da Lei e da Ordem. Brasília: Exercícios e Operações, Disponível em: 〈https://www.defesa.gov.br/exercicios-e-operacoes/garantia-da-lei-e-da-ordem>. Acessado em: <06 de fevereiro de 2019>.
} 
Militarização e democracia no Rio de Janeiro: efeitos e legados da "pacificação" das favelas cariocas.

Revista Ensaios, vol. 14, jan-jun de 2019.

que a definição de quem deve ser objeto deste tipo de ação é alargada suficientemente para incluir, para além dos inimigos externos à segurança nacional (foco da atuação constitucional das Forças Armadas) também criminosos comuns e manifestantes políticos. A grosso modo, para a atual doutrina securitária em vigência no país, os insurgentes somos todos nós. Mas são insurgentes, sobretudo - e é essa dimensão que pretendi destacar neste artigo -, os moradores de favelas, que sempre foram tratados pelo poder público como bandidos ou potencialmente bandidos, envolvidos com o crime ou, pelo menos, coniventes (Machado da Silva (org.), 2008; Farias, 2008b; Rocha, 2013, entre outros). A representação desses territórios e suas populações como inimigos da guerra travada contra o crime fica evidente, por exemplo, na declaração do comandante da Força de Pacificação, General Antônio Carlos de Souza, sobre a ocupação da Maré (entre abril de 2014 e junho de 2015): “É um conflito moderno. Uma guerra irregular, sem fronteiras, com inimigo difuso. E o mais difícil é atuar no meio do povo, com as ruas cheias de gente" (Ministério da Defesa, 2015) ${ }^{26}$.

Graham (2016) salienta que "novo urbanismo militar" não é uma novidade; ao contrário, adiciona novas dimensões contemporâneas às antigas transformações urbanísticas e militares - políticas, culturais e econômicas, que somadas "normalizam" a guerra e os preparativos para ela como elementos centrais da constituição material, político-econômica e cultural das cidades e da vida urbana (2016, pp. 37). Destarte, se a presença de soldados e aparatos militares nas favelas cariocas não é novidade, o acionamento desta possibilidade com maior frequência e maior aceitação a cada vez já indica que o legado da "pacificação", assim como dos outros dispositivos apresentados aqui, é a disseminação da militarização como elemento ordenador da vida social. Hoje a sociedade brasileira debate, através das páginas dos principais jornais, a adoção do modelo dos colégios militares para todas as escolas ${ }^{27}$, o incremento da cooperação com o Estado de Israel na área de segurança, a possibilidade de instalação de uma base militar norte-americana em território brasileiro, entre outros temas que envolvem maior presença militar na vida pública do país. A militarização da vida deixa seus sedimentos por onde passa, produzindo um acúmulo que em outros tempos foi chamado de "entulho

\footnotetext{
${ }^{26}$ Disponível em: <https://www.defesa.gov.br/noticias/15254-complexo-da-mare-forcas-de-pacificacaoja-realizaram-mais-de-65-mil-acoes $>$. Acessado em: $\langle 07$ de fevereiro de 2019〉.

${ }^{27}$ Sobre o tema ver Carneiro \& Sant'Anna, 2018.
} 
Militarização e democracia no Rio de Janeiro: efeitos e legados da "pacificação" das favelas cariocas.

Revista Ensaios, vol. 14, jan-jun de 2019.

autoritário", e do qual ainda lutávamos para nos livrar. Os eventos mais recentes na história brasileira indicam que será mais difícil do que pensávamos.

\section{Referências:}

ALBERnAZ, E. R., Caruso, H., \& Patrício, L. (2007). Tensões e desafios de um policiamento comunitário em favelas do Rio de Janeiro. São Paulo em Perspectiva, 21(2), $39-52$.

ALMENDRA, D. (2014). As UPPs, as Elites e a Imprensa: militarização e consumo no processo de "pacificação" de favelas do Rio de Janeiro. Revista Paranaense de Desenvolvimento, 35(126), 61-89.

ALVES, J. C. S. (2008) Milícias: mudanças na economia política do crime no Rio de Janeiro. En Justiça Global (eds). Segurança, tráfico e milícias no Rio de Janeiro, (pp. 3336). Rio de Janeiro: Fundação Heinrich Böll.

ARAUJO SILVA, M. C., \& Carvalho, M. B. (2015). Circuitos políticos em uma favela pacificada: Os desafios da mediação. Dilemas - Revista de Estudos de Conflito e Controle Social, 8(1), 63-76.

BARROS, R.; FARIAS, J. (2017). Political displacements between the periphery and the center through territories and bodies. Vibrant: Virtual Brazilian Anthropology, 14(3), 120.

BARROS, R. Rio de Janeiro: o caleidoscópio da militarização urbana. In: LEITE, Marcia et. al. (Org.). Militarização no Rio de Janeiro: da pacificação à intervenção. Rio de Janeiro: Mórula, 2018.

BARROS VIEIRA, R. (2016). Sobre o regime empresarial-militar de ocupação das favelas do Rio de Janeiro: Uma análise (crítica) das UPPs. Revista Direito e Práxis, 7(15), 281-304.

BURGOS, M. B. (1998). Dos parques proletários ao Favela-Bairro: as políticas públicas nas favelas do Rio de Janeiro. En Zaluar, A. \& Alvito, M. (org.). Um Século de Favela. (pp. 25-60). Rio de Janeiro: Editora FGV.

BURGOS, M., Pereira, L. F. A., Cavalcanti, M., Brum, M., \& Amoroso, M. (2011). O efeito UPP na percepção dos moradores das favelas. Desigualdade \& Diversidade, 11(49), 25-62.

CANO, I. \& Iott, C. (2008) Seis por meia dúzia. En Justiça Global (eds) Segurança, tráfico e milícias no Rio de Janeiro, (pp. 51-74). Rio de Janeiro: Fundação Heinrich Böll.

CANO, I. \& Duarte, T. (2012). No sapatinho: a evolução das milícias no Rio de Janeiro (2008-2011). Rio de Janeiro: Laboratório de Análise da Violência (LAV-UERJ). 
Militarização e democracia no Rio de Janeiro: efeitos e legados da "pacificação" das favelas cariocas.

Revista Ensaios, vol. 14, jan-jun de 2019.

CANO, I., Borges, D., \& Ribeiro, E. (2012). Os donos do morro. Rio de Janeiro: LAV/UERJ/Fundação Heinrich Böll.

CARVALHO, M. B. (2003). Questão Habitacional e Controle Social: a experiência dos Parques Proletários e a ideologia "higienista-civilizatória". Rio de Janeiro, Brasil: Pontífice Universidade Católica, monografia.

CAVALCANTI, M. (2013). À espera, em ruínas: urbanismo, estética e política no Rio de Janeiro da 'PACificação'. Dilemas: Revista de Estados de Conflito e Controle Social, 6(1), 191-228.

CARNEIRO, S. S. \& Sant'Anna, M. J. G. (2018) Militarização das escolas públicas: tensões e negociações em torno deste modelo de gestão escolar. En Leite, M. P. et al., Militarização no Rio de Janeiro: da "pacificação" à intervenção. (pp. 203-222). Rio de Janeiro: Mórula Editorial.

DA CUNHA, C. V. (2015). O medo do retorno do medo: um ponto de inflexão no programa das UPPs. Dilemas-Revista de Estudos de Conflito e Controle Social, 8(1), 4162.

DAVIES, F. A. (2017). Deodoro: formas de governo para uma "região olímpica". Rio de Janeiro, Brasil: Universidade do Estado do Rio de Janeiro, tesis de doctorado.

FARIAS, J. (2008a). Da asfixia: reflexões sobre a atuação do tráfico de drogas nas favelas cariocas. En Machado da Silva, L. A. (org.), Vida sob cerco: violência e rotina nas favelas do Rio de Janeiro, (pp. 173-190). Rio de Janeiro: FAPERJ/Nova Fronteira.

FARIAS, J. (2008b). Quando a exceção vira regra: os favelados como população "matável" e sua luta por sobrevivência. Teoria \& sociedade, 15(2), 138-171.

FARIAS, J. (2014). Governo de mortes: uma etnografia da gestão de populações de favelas no Rio de Janeiro. Tese (Doutorado em Sociologia)-Instituto de Filosofia e Ciências Sociais, Universidade Federal do Rio de Janeiro, Rio de Janeiro.

FERNANDES, A. (2014). Arte do contornamento e ocupação de moradia no Rio de Janeiro. Revista de Ciências Sociais, Política \& Trabalho. 1(40), p. 311-333.

FOUCAULT, M. (2000). Microfísica do poder. Rio de Janeiro: Graal. Terra, 2017.

História da sexualidade I: a vontade de saber. Rio de Janeiro/São Paulo: Paz \&

GONÇALVES, R. S. (2006). A política, o direito e as favelas do Rio de Janeiro: um breve olhar histórico. URBANA: Revista Eletrônica do Centro Interdisciplinar de Estudos sobre a Cidade, 1(1), 1-23.

GRAHAM, S. (2016). Cidades sitiadas: o novo urbanismo militar. São Paulo: Boitempo Editorial, Coleção Estado de Sítio. 
Militarização e democracia no Rio de Janeiro: efeitos e legados da "pacificação" das favelas cariocas.

Revista Ensaios, vol. 14, jan-jun de 2019.

GUTTERRES, A. S. (2016). O rumor e o terror na construção de territórios de vulnerabilidade na zona portuária do Rio de Janeiro. Mana, 22(1), 179-209.

INSTITUTO BRASILEIRO DE GEOGRAFIA E ESTATÍSTICA - IBGE. (2010). Censo 2010. Brasília: Censo, texto completo: https://ww2.ibge.gov.br/home/estatistica/populacao/censo2010/default.shtm, fecha de consulta 26 de outubro de 2018.

INSTITUTO DE PESQUISA ECONÔMICA E APLICADA \& FÓRUM BRASILEIRO DE SEGURANÇA PÚBLICA. (2018). Atlas da Violência, 2018. Brasil: IPEA, texto completo: http://www.ipea.gov.br/atlasviolencia/, fecha de consulta 06 de fevereiro de 2019.

INSTITUTO DE SEGURANÇA PÚBLICA DO ESTADO DO RIO DE JANEIRO (2019). Disponível em: https://g1.globo.com/rj/rio-de-janeiro/noticia/2019/05/03/rj-baterecorde-na-apreensao-de-fuzis-em-2019-numero-de-mortes-por-intervencao-policial-e-o-maiornos-ultimos-20-anos.ghtml $>$. Acessado em: $<08$ de dezembro de 2019>.

LEITE, M. P. (2000). Entre o individualismo e a solidariedade: dilemas da política e da cidadania no Rio de Janeiro. Revista Brasileira de Ciências Sociais, 15(44), 43-90.

LEITE, M. P. (2017). State, market and administration of territories in the city of Rio de Janeiro. Vibrant: Virtual Brazilian Anthropology, 14(3), 18-22.

LEITE, M. P., Rocha, L. M., Farias, J., \& Carvalho, M. B. (2018). Militarização no Rio de Janeiro: da "pacificação" à intervenção. Rio de Janeiro: Mórula Editorial.

MACHADO DA SILVA, L. A. (org.). (2008) Vida sob cerco: violência e rotina nas favelas do Rio de Janeiro. Rio de Janeiro: Faperj/Nova Fronteira.

MACHADO DA SILVA, L. A. (2010) "Violência Urbana", Segurança Pública e Favelas - o caso do Rio de Janeiro atual. Caderno CRH, 23(59), 283-300.

MAGALHÃES, A. (2013). O "legado" dos megaeventos esportivos. a reatualização da remoção de favelas no Rio de Janeiro. Horizontes Antropológicos, (40), 89-118.

MENEZES, P. V. (2018). Monitorar, negociar e confrontar: as (re) definições na gestão dos ilegalismos em favelas "pacificadas". Tempo Social, 30(3), 191-216.

MIRANDA, A. P. M. (2014) Militarização e direitos humanos: gramáticas em disputa nas políticas de segurança pública no Rio de Janeiro/Brasil. En CESNOVA, Forum Sociológico. Série II. (pp. 11-22). Rio de Janeiro: CESNOVA.

MISSE, M. (2007), "Mercados ilegais, redes de proteção e organização local do crime no Rio de Janeiro". Estudos Avançados, 21(1), 139-157.

PACHECO DE OLIVEIRA, J. (2014). Pacificação e tutela militar na gestão de populações e territórios. Mana, 20(1), 125-161. 
Militarização e democracia no Rio de Janeiro: efeitos e legados da "pacificação" das favelas cariocas.

Revista Ensaios, vol. 14, jan-jun de 2019.

PALERMO, L. C. (2013). Megaeventos e Unidades de Polícia Pacificadora: representações sobre o lugar das favelas no tecido urbano. Ilha Revista de Antropologia, 15(1, 2), 311-330.

PESTANA, M. M. (2018). Complexificação da sociedade civil e ampliação seletiva do Estado brasileiro: o caso do programa de remoções de favelas no Rio de Janeiro, 19571973. Niterói, Brasil: Universidade Federal Fluminense, tesis de doctorado.

RIBEIRO, L.; NEIVA E OLIVEIRA, V.; ALVES DINIZ, A. M. (2016). Los significados de "policía comunitaria" para la Policía Militar Brasileña. Estudios Sociológicos de El Colegio de México, 34(102), 603-637.

RIBEIRO, L.; VILAROUCA, M. G. (2018). " Ruim com ela, pior sem ela": o desejo de continuidade das UPPs para além das Olimpíadas. Revista de Administração Pública, 52(6), 1155-1178.

RIBEIRO, L. C. D. Q.; SANTOS JÚNIOR, O. A. D. (2013). Governança empreendedorista e megaeventos esportivos: reflexões em torno da experiência brasileira. O social em questão, 29(1), 23-42.

ROCHA, L. M. (2013). Uma favela diferente das outras. Rotina, silenciamento e ação coletiva na favela do Pereirão, Rio de Janeiro. Rio de Janeiro: Faperj, Ed. Quartet.

ROCHA, L. M. (2018a). Democracia e militarização no Rio de Janeiro: "pacificação", intervenção e seus efeitos no espaço público. En Leite, M. P. et al. (org), Militarização no Rio de Janeiro: da "pacificação" à intervenção, (pp. 223-239). Rio de Janeiro: Mórula Editorial

ROCHA, L. M. (2018b). Associativismo de moradores de favelas cariocas e criminalização. Estudos Históricos, 31(65), 475-494.

ROCHA, L. M; CARVALHO, M. B. (2018). Da "cidade integrada" à "favela como oportunidade": empreendedorismo, política e "pacificação" no Rio de Janeiro. Cadernos Metrópole, 20(43), 905-924.

ROCHA, L. M., CARVALHO, M. B.; DAVIES, F. A. (2018). Crítica e controle social nas margens da cidade: etnografia de espaços de participação em favelas "pacificadas" do Rio de Janeiro. R@U: Revista de Antropologia Social dos Alunos do PPGASUFSCAR, 10(1), 216-237

ROCHA, L. M.; PALERMO, L.C. (2015). O morro está na calmaria: mídia impressa e o repertório da paz no contexto da pacificação. Dilemas: Revista de Estudos de Conflito e Controle Social, 8(1), 25-40.

VAINER, C. B. (2011). Cidade de Exceção: Reflexões a partir do Rio de Janeiro. Anais do XIV Encontro Nacional da Associação Nacional de Planejamento Urbano (ANPUR), 14(1), 231-248. 
Militarização e democracia no Rio de Janeiro: efeitos e legados da "pacificação" das favelas cariocas. Revista Ensaios, vol. 14, jan-jun de 2019.

VALLADARES, L. P. (1978). Passa-se uma casa: análise do programa de remoção de favelas do Rio de Janeiro. Rio de Janeiro: Zahar Editores.

VALLADARES, L. P. (2005). A invenção da favela: do mito de origem a favela.com. Rio de Janeiro: Ed. FGV.

ZAVERUCHA, J. (2005). A fragilidade do Ministério da Defesa brasileiro. Revista de Sociologia e Política, 107(25), 107-121. 